\title{
Assessment of Magnitude and Associated Factors of Emergence Delirium in the Post Anesthesia Care Unit at Tikur Anbesa Specialized Hospital, Ethiopia
}

\author{
Solomon Assefa ${ }^{1}$,Wosenyeleh A. Sahile ${ }^{1^{*}}$
}

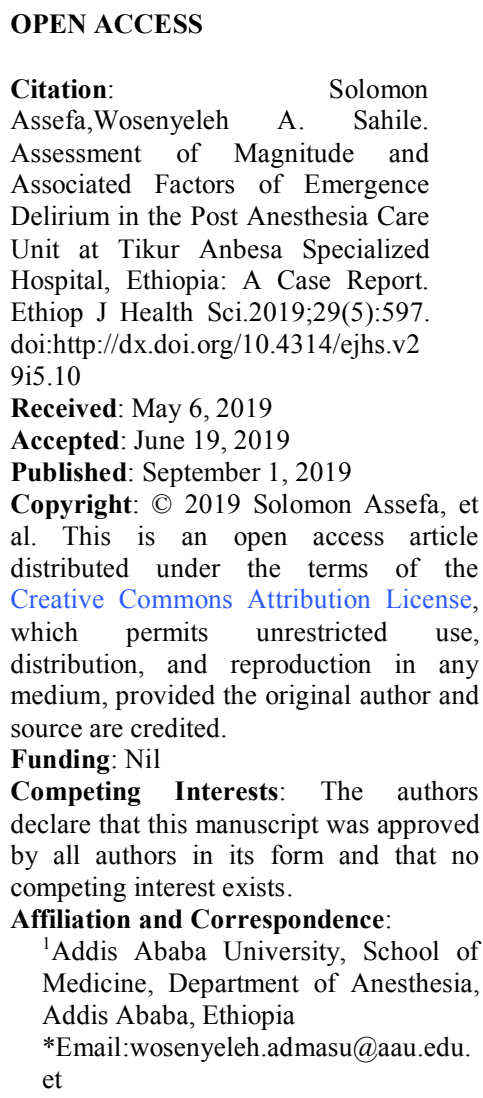

\begin{abstract}
BACKGROUND: Emergence delirium (ED) is known as an acute agitation and confusion occurring during or immediately following emergence from general anesthesia, in the Operation Room or post anesthesia care unit (PACU). ED results in significant morbidity and complications resulting in longer hospital stays. We studied the magnitude and risk factors of $E D$ in the general surgical population.

METHODS: An institution-based prospective cross-sectional study was conducted on patients who underwent surgical procedure at Tikur Anbessa Specialized Hospital, Ethiopia, from March 6 - May 1, 2017. Data was collected using patient interview and chart review. Patients with Richmond Agitation Sedation Scale $\geq+1$ at any time were considered to have emergence delirium/agitation. Categorical data was analyzed using the fishers exact test . Continuous data was analyzed using student t-test. Independent variables were analyzed using binary logistic regression. P-value of $<0.05$ was considered as cutoff point to test for statistically significance.

RESULT: The overall magnitude of Emergence Delirium in this study was $31.7 \%$. Older age $(C I=4.266-12.095, P=0.001)$, substance abuse $(O R=4.6, C I=1.962-10.863, P=0.001)$, preoperative anxiety $(O R=2.4, C I=1.140-5.244, P=0.02)$, benzodiazepine premedication $(\mathrm{OR}=8, \mathrm{CI}=2.788-23.21$, $P=0.001)$, excessive blood loss $(\mathrm{OR}=3.38, C I=1.789-6.412$, $P=0.001)$, postoperative pain $(O R=3.37, C I=2.015$ - 6.934, $P=0.001)$ and longer PACU stay $(C I=18.645-26.766, P=0.001)$ were positively associated with Emergence Delirium.

CONCLUSION: The magnitude of emergence delirium is high and it is associated with older age, substance abuse, premedication with benzodiazepine, excessive blood loss postoperative pain and longer PACU stay.

KEYWORDS: Delirium, Post Anesthesia Care Unit, Magnitude, Risk factors, Ethiopia
\end{abstract}




\section{INTRODUCTION}

Emergence Delirium (ED) is known as acute agitation and confusion occurring during or immediately following emergence from general anesthesia, in the Operationroom (OR) or Post Anesthesia Care Unit (PACU) (1). When patients are delirious, they usually experience disorientation of time, person, and place. Delirium could occur at any time in the perioperative period, but it is more common postoperatively and is said to affect 2 million people every year. Delirium is also commonly underdiagnosed in the postoperative period. A survey of physicians and health professionals found that $78 \%$ of them described delirium as underdiagnosed and only $40 \%$ of the physicians said they routinely screen for delirium (2).

The incidence of delirium varies significantly depending on the type of procedure performed and the presence of risk factors. Incidence varies from $4 \%$ in cataract surgery to $17 \%$ in head and neck surgery and to $35-65 \%$ after orthopedic/hip fracture surgeries (2-4).

Postoperative delirium is a common complication that is affected by several perioperative factors. Older age is frequently mentioned as a major factor. Others include previous delirium occurrence, preexisting cognitive or functional impairment, preoperative administration of drugs like opioids and benzodiazepines. It is also common among patients who alcohol abuse, patients with low postoperative saturation, untreated pain, electrolyte disturbance and low hemoglobin have all been found to be associated with PACU delirium (5-8).

The occurrence of delirium acutely in the PACU could be very dangerous for the patient and may lead to injury, increased pain, hemorrhage, self-extubation and removal of catheters which may lead the PACU staff to restrain the patient. Studies generally agree that the occurrence of delirium is associated with high morbidity and mortality, prolonged hospital stays and higher costs. The complications of delirium can persist for months or more in some individuals. A study on the occurrence of delirium after orthopedic surgery found that $39 \%$ of patients were delirious during discharge, and that the delirium even persisted until 6 months for some patients $(6,9)$.

Data on emergence delirium is relatively scarce. Most studies focus on the development of delirium after discharge from PACU to either intensive care unit (ICU) or outpatient. There are few studies that show the magnitude of delirium in the general surgical population at the emergence phase which is right after admission to PACU. This study aims to assess the incidence and possible risk factors of emergence delirium after anesthesia in Tikur Anbessa Specialized Hospital, Ethiopia.

\section{MATERIALS AND METHODS}

After being approved from the Ethical Board in Addis Ababa University, the study was conducted in Tikur Anbessa University Hospital (Black Lion Hospital) between March 6 and may 12, 2017. A total of 1223 patients underwent surgery at the hospital. The sample size was calculated by single proportion formula using 50\% proportion, 95\% confidence interval and margin of error of $5 \%$. After using correction formula and considering a $10 \%$ non-response rate, a sample size of 306 was obtained. Each morning after obtaining the daily schedule list, patients were selected using systematic random sampling. Every patient who was sampled and admitted to PACU in the study period was included. This 6-bed PACU is located right after the operating theatres. There were 3 full-time nurses, each for two tables. Patients younger than 18 years, patients with dementia and those who underwent psychiatric surgrywere excluded from the study.

A preliminary feasibility pilot study was conducted on 30 patients on the PACU using the Richmond Agitation and Sedation Scale (RASS). The RASS scale was developed to assess the level of agitation and sedation for ICU patients. We felt that it could also be applicable in the PACU. The scale ranges from 4 (combative) to negative 5 (unarousable), with 0 being alert and calm. Initially, patients were classified into non-agitated (o to negative 5) and agitated (1-4). After that, they were classified into 0 (calm and alert) and 1 (restless), 2 (agitated), 3 (very agitated) and 4 (combative) right after being admitted into PACU. Each classification has its own description. A

DOI: http://dx.doi.org/10.4314/ejhs.v29i5.2 
patient with RASS score of greater than one was also considered agitated. The scale is userfriendly. Recovery room nurses were responsible for identifying patients and collecting data.

Data was collected using structured questionnaire. Preoperatively, patients' sociodemographic variables including ASA (American Society of Anesthesiologist's Physical Status), history of substance abuse, any preexisting comorbidity, and anxiety were recorded. The intra and postoperative data included premedication, surgery type and duration, type of anesthesia, type of induction and maintenance agent, usage of analgesics, presence of tracheal tube and urinary catheter, blood loss defined ass intraoperative loss of $>400 \mathrm{ml}$, postoperative pain using numeric rating score (NRS) and PACU stay time. For patients with emergence delirium, the score was recorded, and the patients were given the necessary treatments including analgesics antiemetics and anxiolytics.

Data were analyzed using SPSS ${ }^{\circledR}$ (Statistical Package for Social Sciences) version 20 software. Categorical data were analyzed using the fishers exact test where appropriate. Continuous data were analyzed using student t-test. All Independent variables were analyzed using binary logistic regression. Odds ratio, 95\% confidence interval and p-value were computed to identify associated factors and to determine the strength of the association. Variables with a p-value of less than 0.1 in the univariate analysis were taken to multivariate analysis, and p-value of $<0.05$ was considered as a cutoff point to test for statistically significance.

\section{RESULTS}

Sociodemographic and preoperative variables: There were 306 study participants: 145 males and 161 females. The participants had a mean age of $44.53 \pm 16.61$ with a range of $18-82$. The demographic and perioperative data of the agitated and non-agitated patients are shown in Tables 1 and 2. Patients with delirium were much older than non-delirious patients. Of the preoperative data, age, substance abuse preoperative anxiety and premedication with benzodiazepine were found to be statistically significant. No major differences observed in the other variables.

Table 1: Logistic regression, preoperative risk factors of emergence delirium-comparison between agitatedand non-agitated patients

\begin{tabular}{|c|c|c|c|c|c|}
\hline Variable & & All patients & Agitated(\%) & Non Agitated (\%) & $\mathrm{P}$ value \\
\hline Total & & 306 & $97(31.7)$ & $209(68.3)$ & \\
\hline Age & & $44.53 \pm 16.61^{\S} \mathrm{yr}$. & $50.11 \pm 17.45^{\S} \mathrm{yr}$. & $41.93^{\S} \pm 15.574^{\S} \mathrm{yr}$. & $0.001^{\dagger}$ \\
\hline Sex & Male & 145 & $48(33.1)$ & 97 (66.9) & $0.616^{*}$ \\
\hline & Female & 161 & $49(30.4)$ & $112(33.1)$ & \\
\hline ASA physical status & ASA I & 196 & $66(33.7)$ & $130(66.3)$ & $0.126^{*}$ \\
\hline & $\begin{array}{l}\text { ASA II } \\
\text { ASA III }\end{array}$ & $\begin{array}{l}102 \\
8\end{array}$ & $\begin{array}{l}31(30.4) \\
0\end{array}$ & $\begin{array}{l}71(69.6) \\
8(100)\end{array}$ & \\
\hline Co-existing disease & $\begin{array}{l}\text { Yes } \\
\text { No }\end{array}$ & $\begin{array}{l}75 \\
231\end{array}$ & $\begin{array}{l}24(32) \\
73(31.6)\end{array}$ & $\begin{array}{l}51(68) \\
158(68.4)\end{array}$ & $0.94 *$ \\
\hline Substance abuse & $\begin{array}{l}\text { Yes } \\
\text { No }\end{array}$ & $\begin{array}{l}40 \\
266\end{array}$ & $\begin{array}{l}22(55) \\
75(28.2)\end{array}$ & $\begin{array}{l}18(45) \\
191(71.8)\end{array}$ & $0.001 *$ \\
\hline Preoperative anxiety & $\begin{array}{l}\text { Yes } \\
\text { No }\end{array}$ & $\begin{array}{l}53 \\
253\end{array}$ & $\begin{array}{l}23(43.4) \\
74(29.2)\end{array}$ & $\begin{array}{l}30(56.6) \\
179(70.8)\end{array}$ & $0.044 *$ \\
\hline $\begin{array}{l}\text { Premedication with } \\
\text { benzodiazepine }\end{array}$ & $\begin{array}{l}\text { Yes } \\
\text { No }\end{array}$ & $\begin{array}{l}26 \\
280\end{array}$ & $\begin{array}{l}18(69.2) \\
79(28.2)\end{array}$ & $\begin{array}{l}8(30.8) \\
201(71.8)\end{array}$ & $0.001 *$ \\
\hline
\end{tabular}

ASA American society of Anesthesiologist's physical status, *Pearson chi square, †two sample t-test, §mean (range or SD)

DOI: http://dx.doi.org/10.4314/ejhs.v29i5.10 
Table 2: Logistic regression: Intra and post-operative risk factors of emergence delirium. Comparison between Agitatedand Non Agitated patients

\begin{tabular}{|c|c|c|c|c|c|}
\hline \multicolumn{2}{|l|}{ Variable } & \multirow{2}{*}{$\begin{array}{l}\text { All patients } \\
306\end{array}$} & \multirow{2}{*}{$\begin{array}{l}\text { Agitated(\%) } \\
97(31.7)\end{array}$} & \multirow{2}{*}{$\begin{array}{l}\text { Non Agitated (\%) } \\
209(68.3)\end{array}$} & \multirow[t]{2}{*}{$\begin{array}{l}\mathrm{P} \\
\text { value } \\
\end{array}$} \\
\hline Total & & & & & \\
\hline \multirow[t]{7}{*}{ Type of surgery } & $\begin{array}{l}\text { General } \\
\text { surgery }\end{array}$ & 74 & $25(33.5)$ & $49(66.2)$ & \multirow[t]{7}{*}{$0.045^{*}$} \\
\hline & Urology & 40 & $15(37.5)$ & $25(62.5)$ & \\
\hline & Neuro surgery & 39 & $22(56.4)$ & $17(43.6)$ & \\
\hline & ENT & 41 & $6(14.6)$ & $35(85.4)$ & \\
\hline & Cardiothoracic & 56 & $17(30.4)$ & $39(69.6)$ & \\
\hline & Gynecology & 4 & $3(75)$ & $1(25)$ & \\
\hline & Orthopedics & 52 & $14(26.9)$ & $38(73.1)$ & \\
\hline \multirow[t]{5}{*}{ Induction type } & Thiopental & 152 & $35(23)$ & $117(117)$ & \multirow[t]{5}{*}{$0.001^{*}$} \\
\hline & Propofol & 110 & $38(34.5)$ & $72(62.5)$ & \\
\hline & Ketamine & 19 & $5(26.3)$ & $14(73.7)$ & \\
\hline & Ketofol & 21 & $6(28.6)$ & $15(71.4)$ & \\
\hline & Inhalational & 4 & 4 & 0 & \\
\hline \multirow{2}{*}{\multicolumn{2}{|c|}{ Duration of surgery }} & $65.52 \pm 19.82^{\S} \mathrm{min}$ & (97) & (209) & \multirow[t]{2}{*}{$0.001^{\dagger}$} \\
\hline & & & $\begin{array}{l}81.03 \pm 16.088^{\S} \\
\text { min. }\end{array}$ & $58.33 \pm 17.113^{\S} \mathrm{min}$ & \\
\hline \multirow{2}{*}{$\begin{array}{l}\text { Excessive blood } \\
\operatorname{loss}^{\mathrm{a}}\end{array}$} & Yes & 78 & $42(53.8)$ & $36(46.2)$ & \multirow[t]{2}{*}{$0.001 *$} \\
\hline & No & 228 & $55(24.1)$ & $173(75.9)$ & \\
\hline \multirow{2}{*}{$\begin{array}{l}\text { Presence of } \\
\text { tracheal tube }\end{array}$} & Yes & 1 & 0 & 1 & \multirow[t]{2}{*}{$0.495^{*}$} \\
\hline & No & 305 & $97(31.8)$ & $208(68.2)$ & \\
\hline \multirow{2}{*}{$\begin{array}{l}\text { Presence of } \\
\text { urinary catheter }\end{array}$} & Yes & 185 & $66(35.7)$ & $119(64.3)$ & \multirow[t]{2}{*}{$0.065^{*}$} \\
\hline & No & 121 & $31(25.6)$ & $90(74.4)$ & \\
\hline PACU stay time & & $65.2 \pm 19.8^{\S} \mathrm{min}$. & $\begin{array}{l}(97) \\
81.03 \pm 16.08^{\S} \\
\text { min. }\end{array}$ & $\begin{array}{l}(209) \\
58.33 \pm 17.11^{\S} \mathrm{min} .\end{array}$ & $0.001^{\dagger}$ \\
\hline \multirow{2}{*}{$\begin{array}{l}\text { NRS for } \\
\text { postoperative } \\
\text { pain }\end{array}$} & $\mathrm{NRS} \geq 4$ & 92 & $47(51.1)$ & $45(48.9)$ & \multirow[t]{2}{*}{$0.001 *$} \\
\hline & $\mathrm{NRS}<4$ & 214 & $50(23.4)$ & $164(76.6)$ & \\
\hline
\end{tabular}

Intra and postoperative variables: Surgeries in the General surgery category were most routinely performed. Thiopental is the most regularly used induction agent. The mean surgical time was 65.52 \pm 19.82 with the range being $20-420$ minutes. Patients stayed in the PACU from 20-120 minutes (mean time $=65.2 \pm 19.8$ minutes). Type of surgery, induction type, excessive blood loss,
PACU stay time and postoperative pain were found to be clinically significant variables.

Magnitude of delirium: Among the 306 patients included in this study, the magnitude of confirmed emergence delirium in the PACU was 97 (31.7\%). Out of this, nearly half (47\%) of the patients were combative and $28 \%$ very agitated (Figure 1 ). 


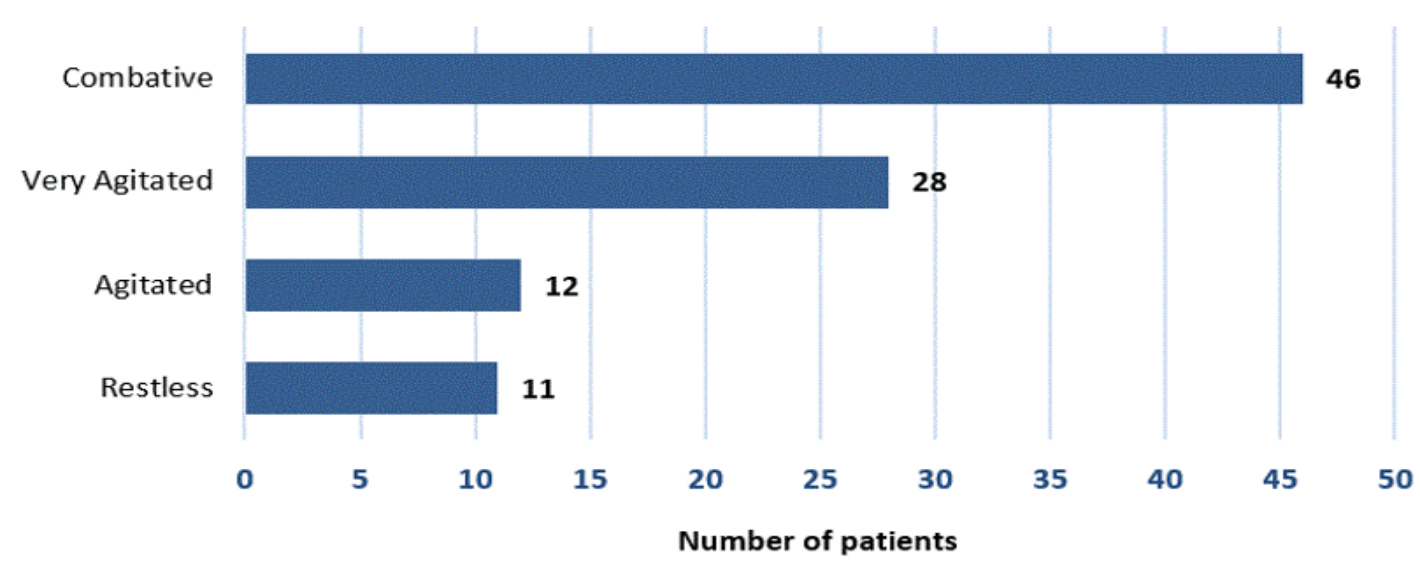

Fig 1 Occurrence and Degree of Delirium

Univariate and multivariate analysis of risk factors for emergence delirium: Univariate analysis found that the occurrence of delirium correlated positively with the following variables. ASA physical status, age, premedication with benzodiazepine, social history of substance abuse, preoperative anxiety, premedication with benzodiazepine, induction agent used, excessive blood loss, PACU stay and postoperative pain.
Multivariate logistic regression analysis was conducted using the risk factors that were established by the univariate analysis. It demonstrated that older age, substance abuse, premedication with benzodiazepine, preoperative anxiety, excessive blood loss, postoperative numeric rating scale of $\geq 4$ and longer PACU stay were found to be significant determinants for emergence delirium (Table 3).

Table 3: Multivariate analysis for risk factors of emergence delirium

\begin{tabular}{llll}
\hline Variable & Odds ratio & P value $<0.05$ & CI (95\%) \\
\hline Age & - & $0.001^{\dagger}$ & $4.266-12.095$ \\
Substance abuse & 4.6 & 0.001 & $1.962-10.863$ \\
Premedication with BZD & 8 & 0.001 & $2.788-23.21$ \\
Preoperative anxiety & 2.44 & 0.02 & $1.140-5.244$ \\
Excessive blood loss & 3.38 & 0.001 & $1.789-6.412$ \\
NRS $\geq 4$ & 3.73 & 0.001 & $2.015-6.934$ \\
PACU stay time & - & $0.001^{\dagger}$ & $18.645-26.766$ \\
\hline
\end{tabular}

${ }^{\dagger}$ two sample t-test

\section{DISCUSSION}

In our study, the magnitude of emergence delirium in the general surgical population was $31.7 \%$. this is a relatively larger finding. The occurrence of delirium varies widely among different fields and surgical specialties, from $4 \%$ to $65 \%(2-3)$. Moreover, it was found that of all agitated patients, the majority were either combative (46\%) or very agitated $(28 \%)$. Emergence delirium was diagnosed using the RASS (Richmond Agitation and Sedation Score) scale. There are several scales for assessing emergence agitation like the Riker Agitation Sedation Score and Motor Activity Assessment Scale. Studies have shown that the RASS scale has an excellent inter-rater consistency and ease of use $(10,11)$. Although the scales are primarily made for assessing ICU patients, we felt that such scales can also be used in the PACU. Based on the analysis, it was also

DOI: http://dx.doi.org/10.4314/ejhs.v29i5.10 
found that older age, substance abuse, premedication with benzodiazepine, excessive blood loss, postoperative pain and longer PACU stay were found to be significantly associated with emergence delirium.

Advanced age is a well-known risk factor for delirium. Several studies have consistently shown that in different surgical specialties, the most constant predicting variable for delirium is advanced age (12-14). In advanced age, there is a significant pharmacodynamic and pharmacokinetic change which will result in substantial side effect of the drug used perioperatively. Furthermore, older patients have reduced ability for surgical and anesthesia-related stress regulation (15).

Patients who were consuming alcohol regularly, smoking cigarette or chewing Khat (a mildly stimulant substance chewed for a recreational purpose), were considered at risk for ED. Patients who either took one or a multitude of those agents were highly susceptible to ED. Studies have shown an association between substance abuse and delirium occurrence (16). Although the cutoff points to define levels of abuse were different (17), in our study, levels of alcohol and cigarette and Khat consumption were not quantified. Patients were asked if they uses the substances regularly or not at all.

Preoperative anxiety and emergence delirium are closely interrelated problems. This is especially true in children (18). Although our study did not use any structured questionnaire to diagnose anxiety, the use of such tools have also been shown to increase the anxiety level (19). In our study, patients who were premedicated with benzodiazepine were 8 times more likely to be delirious than patients who were not. This might be surprising given that such drugs are prescribed to alleviate apprehension. Various reports have conflicting information: some report that BZD hasprotective effects (18-20), while others report a higher rate of delirium especially in older patients (19-21). The effects could be attributed to the paradoxical effects of BZDs, effects such as irritability, aggressiveness, and confusion that especially result with repeated doses. Because of the study design, it is difficult to ascertain the exact role of BZDs.
An Excessive blood loss intraoperatively was associated with emergence delirium. Studies show similar results (18-20). The resulting hypotension with a drop in cerebral blood flow is implicated to be behind the ED. Extreme hypotension that is either deliberate or resulting from bleeding should be short-lived to prevent ED (22). Patients who were in pain in PACU were more likely to be in ED. Although patients were administered the standard analgesics in our PACU, which includes diclofenac, tramadol and sometimes meperidine. the findings still show that pain management is not well addressed. Untreated pain can result in a multitude of problems which include apprehension, confusion and aggressiveness (23).

Emergence delirium can result in significant mortality and morbidity with longer hospital stays. It requires more staff as well as resources and results in dangerous complications like sudden self-extubation and removal of catheters. In our study, delirious patients stayed longer in the PACU than non-delirious ones.

In conclusion we investigated the magnitude of emergence delirium in PACU in the general surgical population. The result showed that ED occurs frequently and is undermanaged. Few studies have given attention to ED that occurs in PACU. The following risk factors were associated with ED: older age, substance abuse, premedication with a benzodiazepine, excessive blood loss, postoperative pain and longer PACU stay. Emergence delirium is associated with high postoperative complications which lead to longer PACU stays. The significant mortality and morbidity imposed by ED could be reduced by developing a prevention strategy to deal with the predisposing risk factors beginning from the preoperative period until patient discharge.

Our study had some limitations primarily the relatively larger confidence intervals which is a result of our smaller sample size. Assessing ED after PACU discharge might not have given us the complete picture of the severity and risk factors of ED.

\section{REFERENCES}

DOI: http://dx.doi.org/10.4314/ejhs.v29i5.2 
1. Card E, Pandharipande P, Tomes C, Lee C, Wood J, Nelson D, Graves A, Shintani A, Ely EW, Hughes C. Emergence from general anaesthesia and evolution of delirium signs in the post-anaesthesia care unit. British Journal of Anaesthesia. 2014;115(3):411-7.

2. Amador LF, Goodwin JS. Postoperative delirium in the older patient. Journal of the American College of Surgeons. 2005 May 1;200(5):767-73.

3. Milstein A, Pollack A, Kleinman G, Barak Y. Confusion/delirium following cataract surgery: an incidence study of 1-year duration. International Pychogeriatrics. 2002;14(3):301-6.

4. Booka E, Kamijo T, Matsumoto T, Takeuchi M, Kitani T, Nagaoka M, Imai A, Iida $Y$, Shimada A, Takebayashi K, Niihara $M$. Incidence and risk factors for postoperative delirium after major head and neck cancer surgery. Journal of Cranio-Maxillofacial Surgery. 2016;44(7):890-4.

5. Marcantonio E, Ta T, Duthie E, Resnick NM. Delirium severity and psychomotor types: their relationship with outcomes after hip fracture repair. Journal of the American Geriatrics Society. 2002;50(5):850-7.

6. Wang SG, Goh EK, Lee BJ, Chon KM. Factors associated with postoperative delirium after major head and neck surgery. Annals of Otology, Rhinology \& Laryngology. 2004;113(1):48-51.

7. Litaker D, Locala J, Franco K, Bronson DL, Tannous Z. Preoperative risk factors for postoperative delirium. General Hospital Psychiatry. 2001;23(2):84-9.

8. 8.Weed HG, Lutman CV, Young DC, Schuller DE. Preoperative identification of patients at risk for delirium after major head and neck cancer surgery. The Laryngoscope. 1995 Oct 1;105(10):1066-8.

9. Lepouse C, Lautner CA, Liu L, Gomis P, Leon A. Emergence delirium in adults in the post-anaesthesia care unit. BJA: British Journal of Anaesthesia. 2006;96(6):747-53.

10. Sessler CN, Gosnell MS, Grap MJ, Brophy GM, O'neal PV, Keane KA, Tesoro EP, Elswick RK. The Richmond AgitationSedation Scale: validity and reliability in adult intensive care unit patients. American Journal of Respiratory And Critical Care Medicine. 2002;166(10):1338-44.

11. Riker RR, Fraser GL, Simmons LE, Wilkins ML. Validating the Sedation-Agitation Scale with the Bispectral Index and Visual Analog Scale in adult ICU patients after cardiac surgery. Intensive Care Medicine. 2001;27(5):853-8.

12. Gallagher TK, McErlean S, O'farrell A, Hoti $\mathrm{E}$, Maguire $\mathrm{D}$, Traynor OJ, Conlon $\mathrm{KC}$, Geoghegan JG. Incidence and risk factors of delirium in patients post pancreaticoduodenectomy. $\quad H P B$. 2014;16(9):864-9.

13. Takeuchi M, Takeuchi H, Fujisawa D, Miyajima K, Yoshimura K, Hashiguchi S, Ozawa S, Ando N, Shirahase J, Kitagawa Y, Mimura M. Incidence and risk factors of postoperative delirium in patients with esophageal cancer. Annals of Surgical oncology. 2012;19(12):3963-70.

14. Yoshimura Y, Kubo S, Shirata K, Hirohashi K, Tanaka H, Shuto T, Takemura S, Kinoshita H. Risk factors for postoperative delirium after liver resection for hepatocellular carcinoma. World Journal of Surgery. 2004;28(10):982-6.

15. Sprung J, Roberts RO, Weingarten TN, Nunes Cavalcante A, Knopman DS, Petersen RC, Hanson AC, Schroeder DR, Warner DO. Postoperative delirium in elderly patients is associated with subsequent cognitive impairment. BJA: British Journal of Anaesthesia. 2017;119(2):316-23.

16. Patti R, Saitta M, Cusumano G, Termine G, Di Vita G. Risk factors for postoperative delirium after colorectal surgery for carcinoma. European Journal of Oncology Nursing. 2011;15(5):519-23.

17. Dasgupta M, Dumbrell AC. Preoperative risk assessment for delirium after noncardiac surgery: a systematic review. Journal of the American Geriatrics Society. 2006;54(10):1578-89.

18. Kain ZN, Caldwell-Andrews AA, Maranets I, McClain B, Gaal D, Mayes LC, Feng R, Zhang H. Preoperative anxiety and emergence delirium and postoperative maladaptive 
behaviors. Anesthesia \& Analgesia. 2004;99(6):1648-54.

19. Maltby N, Mayers MF, Allen GJ, Tolin DF. Anxiety sensitivity: Stability in prospective research. Journal of anxiety disorders. 2005 Dec 31;19(6):708-16.

20. Schor JD, Levkoff SE, Lipsitz LA, Reilly $\mathrm{CH}$, Cleary PD, Rowe JW, Evans DA. Risk factors for delirium in hospitalized elderly. Jama. 1992;267(6):827-31.

21. Lepouse C, Lautner CA, Liu L, Gomis P, Leon A. Emergence delirium in adults in the post-anaesthesia care unit. BJA: British Journal of Anaesthesia. 2006;96(6):747-53.

22. Echigoya Y, Kato H. Causes of postoperative delirium after abdominal surgery in elderly patients. Masui. The Japanese Journal of Anesthesiology. 2007;56(8):932-6.

23. 23.Radtke FM, Franck M, Hagemann L, Seeling M, Wernecke KD, Spies CD. Risk factors for inadequate emergence after anesthesia: emergence delirium and hypoactive emergence. Minerva Anestesiologica. 2010;76(6):394-403. 